\title{
A rare, ectopic (intravesical) location of a missing intrauterine contraceptive device. A case report
}

\author{
Adewale Eri-oluwa Oguntoyinbo, ${ }^{1}$ Ifetoluwani Oluwadunsin Oguntoyinbo, ${ }^{2}$ \\ Oluwabunmi Esther Oguntoyinbo, ${ }^{3}$ Issa Babatunde Aremu ${ }^{4}$ \\ ${ }^{1}$ Blue Cross Diagnostic center, Ilorin, University of Ilorin, Ilorin, Kwara State; ${ }^{2}$ Blue Cross Diagnostic \\ Center, Ilorin, Kwara State; ${ }^{3}$ University of Ilorin Teaching Hospital, Ilorin, Kwara State; ${ }^{4}$ University of \\ Ilorin Teaching Hospital, University of Ilorin, Ilorin, Kwara State, Nigeria
}

\begin{abstract}
Ectopic location of Intrauterine Contraceptive Device (IUCD) or its migration from the normal position in the uterine fundus is a frequently encountered complication. It varies from uterine expulsion to displacement into the endometrial canal to uterine perforation or intravesical migration, which is an extremely rare case. Ultrasonography was used in the diagnoses of this reported case of an ectopic intravesical IUCD.
\end{abstract}

\section{Introduction}

Intrauterine Contraceptive Device (IUCD) is a long acting contraception and is regarded as one of the most effective reversible

\footnotetext{
Correspondence: Adewale Erioluwa Oguntoyinbo, Blue Cross Diagnostic center, Ilorin, University of Ilorin, Ilorin, Kwara StateNigeria. E-mail: Waleogunt2004@yahoo.com
}

Key words: Intravesical, intrauterine, contraceptive, ultrasonography, radiography.

Availability of data and materials: All data underlying the findings are fully available.

Ethics approval and consent to participate: No ethical committee approval was required for this case report by the Department, because this article does not contain any studies with human participants or animals. Informed consent was obtained from the patient included in this study.

Consent for publication: The patient gave her written consent to use her personal data for the publication of this case report and any accompanying images.

Received for publication: 18 December 2020.

Revision received: 23 January 2021.

Accepted for publication: 29 January 2021.

This work is licensed under a Creative Commons Attribution NonCommercial 4.0 License (CC BY-NC 4.0).

(C) Copyright: the Author(s), 2021

Licensee PAGEPress, Italy

Annals of Clinical and Biomedical Research 2021; 2:130

doi:10.4081/acbr.2021.130 birth control method. An estimate of about 128 million women all over the world is using IUCD. The IUCD is commonly used because of its cost-effectiveness and low complication rates. ${ }^{1,2}$ However, migration of the IUCD from its normal position in the uterine fundus is a frequently encountered complication, varying from uterine expulsion to displacement in the endometrial canal to uterine perforation. ${ }^{3}$ Uterine perforation and intravesical migration is extremely rare. Once the IUCD has penetrated the bladder, it usually becomes encrusted with calculi and is associated with lower urinary tract symptoms. ${ }^{1-4}$ The IUCD strings are used to monitor and remove the device. The presence of the string in the vagina usually suggests that the IUCD is in situ. A missing string is regarded as the first sign of displacement in approximately $80 \%$ of cases. ${ }^{5-10}$ However, this sign was not documented in this report but the patient was referred on the basis of inability to remove the IUCD after several attempts at removing it.

\section{Case Report}

A 40-years-old, multiparous patient was referred from an outskirt, private hospital for abdominal X-ray examination with the history of inability to remove an IUCD haven tried unsuccessfully for the past two years, visiting various clinics without a positive outcome. A recent attempt by a private physician to remove it, through uterine evacuation was unsuccessful, and so the patient was referred for an anterior-posterior abdominal X-ray examination, which showed the IUCD within the pelvic cavity plus a ball like opacity on one of the limbs of the device, consistent with calcification or a calculus. On the basis of this, a pelvic ultrasound examination for further evaluation and to delineate the relationship between the IUCD, calculus, uterus and urinary bladder was done. It is to be noted that no previous abdominal or pelvic imaging examinations had been done before the patient was sent for the Xray examination (Figure 1). The result showed an inverted image of a copper T IUCD (that is, the T-shaped limbs were down while the trunk of the device was directed cephalad (up) in the AP view). And there was an added ball-shaped opacity on one of the limbs.

To confirm the actual location of the IUCD in the pelvic structures, a pelvic ultrasound examination was requested for and this revealed an echogenic structure with high acoustic shadowing, with part of it connected to the anterior uterine wall in the transverse plane (Figure 2) while in the longitudinal/saggital plane, it was contiguous with the anterior uterine wall (Figure 3). A normal pelvic sonograph showing the uterus and urinary bladder is hereby added for comparison (Figure 4). An oblique x-ray view of the pelvis was also done to further confirm the connection between the calculus and one of the limbs of the device which forms the nidus for the calcium deposition within the urinary bladder (Figure 5). 


\section{Discussion}

Ectopic location of IUCD is a known occurrence or clinical complain and is usually detected when the patient failed to fill the tag. Intestinal obstruction, vomiting, evisceration of viscous, failure of the device, painful abdominal cramps, expulsion, menstrual disturbances, increased risk of ectopic pregnancy, septic and spontaneous abortion in case of pregnancy with IUCD in situ and pelvic inflammatory disease are the possible complications associated with IUCD. ${ }^{7}$ On rare occasions, it may be abnormally located above the diaphragm or complete/partial uterine perforation like the present case discussed, in which it was located within the urinary bladder after perforation of the uterine wall. Inadvertent duplicate insertion of the IUCD has also been reported. ${ }^{8}$

The thrust of this paper is to let physicians know that there is need for a holistic approach in the management of missing IUCD. The radiologist plays an important role in the diagnosis of IUCD migration and should be familiar with its appearance at multiple imaging modalities. ${ }^{1}$ The ultrasound has been the best imaging modality available for the location of a missing IUCD. ${ }^{11-12}$ This is because it is safe, cheap, non-invasive, accessible and does not involve the use of ionizing radiation. However, the usefulness of

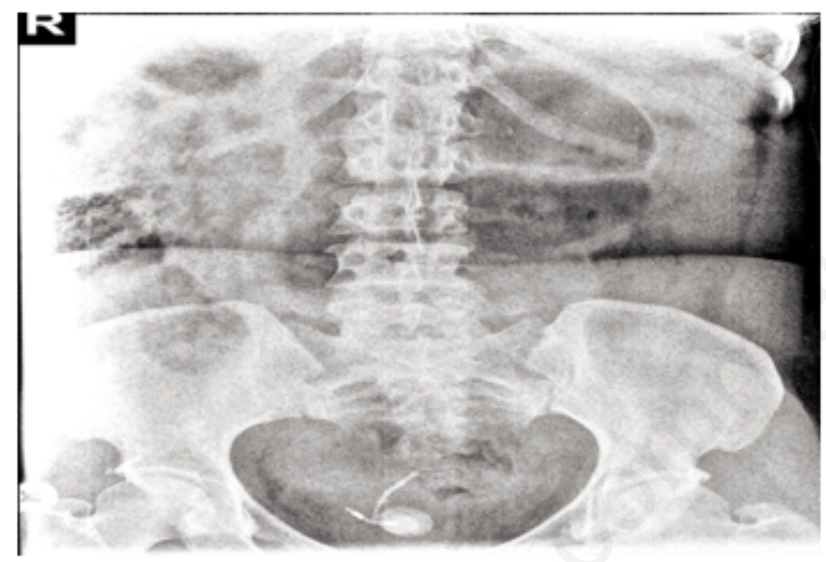

Figure 1. Radiograph showing the IUCD within the pelvic cavity with a ball-like opacity on one of the limbs of the device.

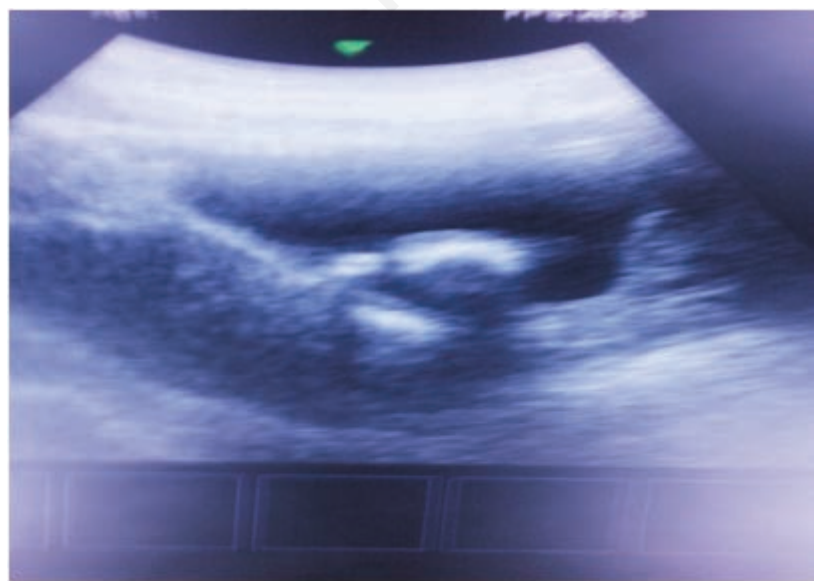

Figure 2. The transverse pelvic ultrasound examination with the IUCD to be extra uterine. plain abdominal X-rays and CT should not be overlooked. In other words, they should embrace the use of imaging modality wherever it is available and if not, referrals should be made before any inappropriate intervention to retrieve the device is done with proper

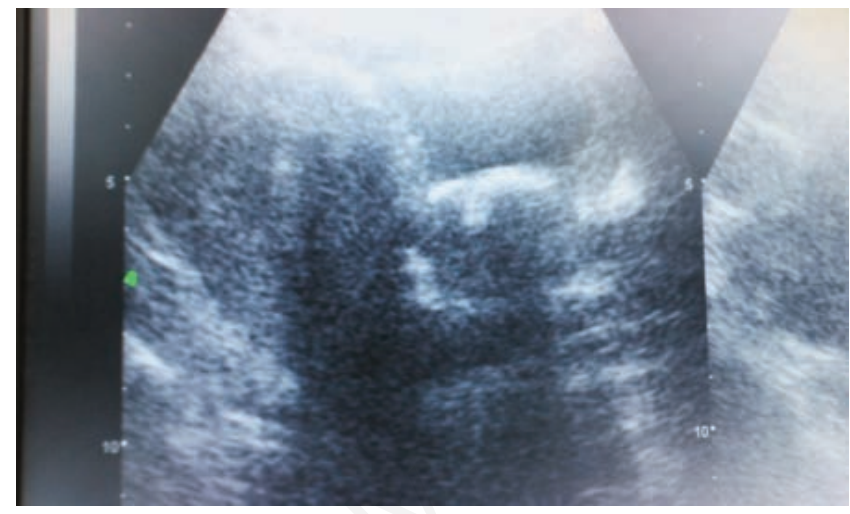

Figure 3. The longitudinal/sagittal pelvic ultrasound examination, with the IUCD contiguous with the anterior uterine wall of the uterus.

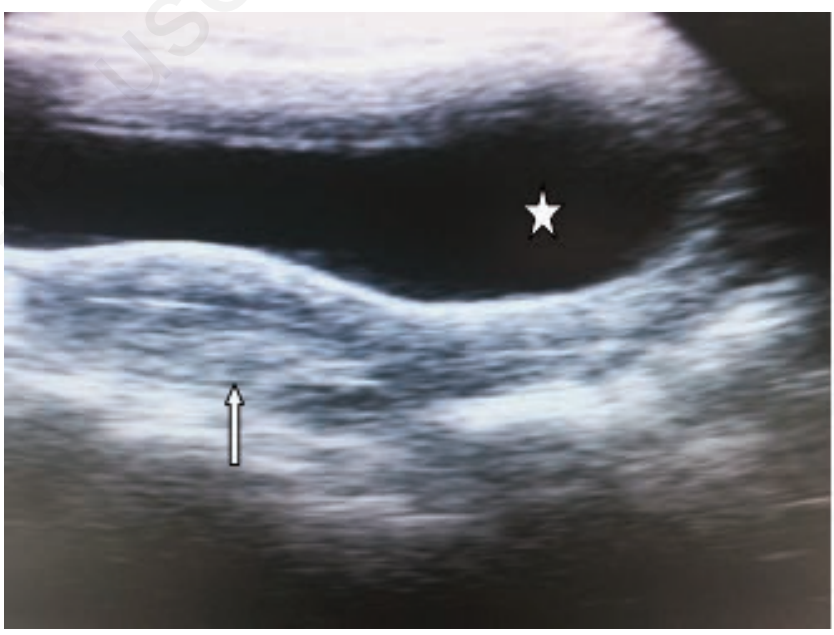

Figure 4. A normal uterus in a sagittal plane (Arrowed) and the urinary bladder anterior to it (starred).

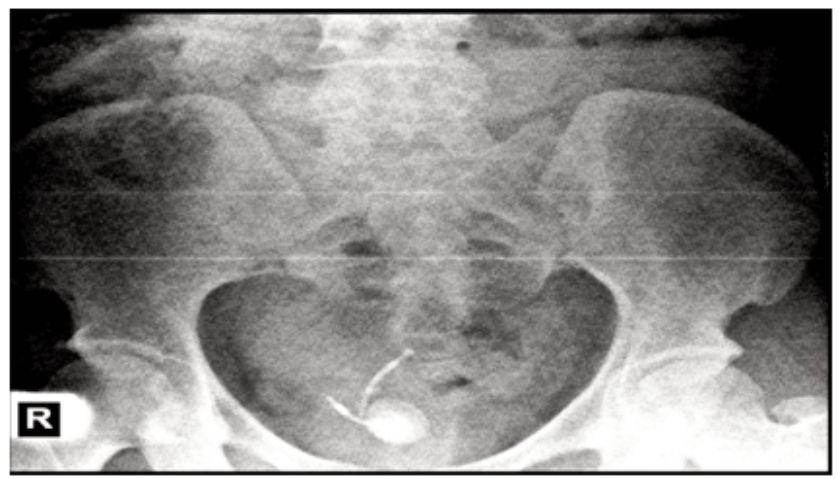

Figure 5. An oblique $\mathrm{X}$-ray view of the pelvis which confirmed the attachment of the stone to the ectopic IUCD. 
history taken. For instance, further questioning of the patient during the investigation confirmed she has been having intermittent haematuria, with severe pain but she didn't mention this to the referring physician because he never asked and she also thought it was part of her menstruation. In the present case, if the proper radiological/imaging assessment has been made within the 2 years period, the IUCD would have been located before the bladder stone formation. It's also possible that the migration into the bladder could have been due to the inappropriate intervention.

\section{Conclusions}

In conclusion, missing IUCD is better evaluated through proper radiological/imaging assessment. This case emphasizes the need for diligent evaluation of cases by the physician and the imaging scientist so that there will be no mismanagement or further compilation.

\section{References}

1. Dietrick DD, Issa MM, Kabalin JN, Bassett JB. Intravesical migration of intrauterine device. Journal Urol 1992;147:132-4.

2. Ghanem MA, Sultan SM, Ghanem AA, Zanaty FM. Double intravesical migration of intrauterine device: presented with vesical stone formation. World J Nephrol Urol 2013;2:79-81.

3. Boortz HE, Margolis DJ, Ragavendra N, et al. Migration of intrauterine devices: radiologic findings and implications for patient care. Radiographics 2012;32:335-52.
4. Gillis E, Chhiv N, Kang S, et al. Case of urethral foreign body: IUD perforation of the bladder with calculus formation. California J Emerg Med 2006;7:47.

5. Özgür A, Şişmanoğlu A, Yazici C, et al. Intravesical stone formation on intrauterine contraceptive device. Int Urol Nephrol 2004;36:345-8.

6. Sataa S, Sami BR, Karim C, Horchani A. Bladder calculus resulting from the migration of an intrauterine contraceptive device: A report of ten cases. Nephro-urol Monthly 2011;3:5461.

7. Gardyszewska A, Niewiadomska-Kowalczyk M, Szymańska B, et al. Extrauterine mislocated IUD. Ginekologia Polska 2009;80:942.

8. Jindal S, Sharma SS, Ikomi A. Spontaneous breakage and expulsion of a stem fragment of levonorgestrel intrauterine system (Mirena) following duplicate insertion. Arch Gynecol Obstet 2009;279:95-7.

9. Heinonen PK, Merikari M, Paavonen J. Uterine perforation by copper intrauterine device. Eur J Obst Gynecol Reprod Biol 1984; 17:257-61.

10. Ozgun MT, Batukan C, Serin IS, et al. Surgical management of intra-abdominal mislocated intrauterine devices. Contraception 2007;75:96-100.

11. Rani SS, Krishna S. Multiple intrauterine devices in a pregnant uterus. J Obst Gynecol India 2005;55:551-2.

12. Ibitoye BO, Aremu AA, Onuwaje MA, Ayoola OO. What is the fate of the missing intrauterine contraceptive device? Tropical Doctor 2009;39:221-3. 